\title{
Adequacy of contraception and missed opportunities for provision in a genitourinary medicine setting
}

\author{
Sharon Moses, Mia Huengsberg
}

\begin{abstract}
Background and methodology Sexually active women presenting to genitourinary medicine (GUM) clinics are at risk of both sexually transmitted infections and unwanted pregnancies. Emergency hormonal contraception is the only contraceptive service provided in our GUM clinic in Birmingham, UK. We wanted to assess whether contraception use was adequate in women attending our clinic and whether we were missing opportunities to provide more reliable contraception. All new female patients attending the clinic in January 2006 had their notes reviewed to determine current contraception, adequacy of use and contraceptive advice given.
\end{abstract}

Results A total of 266 women were eligible for contraception. Overall, $148(56 \%)$ of the women used reliable methods. Fifty-five (21\%) women were using no contraception and not planning a pregnancy. The under-20s, over-30s and ethnic minorities were more likely to use inadequate or no contraception.

Discussion and conclusions Almost half (43\%) the women attending our GUM clinic had inadequate or no contraception, and in addition documentation of contraceptive advice and further information was poor $(5 \%)$. Young people and ethnic minorities seem particularly vulnerable and at present we are not addressing their contraceptive needs. We plan to conduct a prospective survey to assess this issue further and address feasibility for an on-site contraceptive service.

Keywords contraception, genitourinary medicine, information provision, sexually transmitted infections

J Fam Plann Reprod Health Care 2007; 33(3): 208-210

(Accepted 16 December 2006)

\section{Introduction}

The majority of women attending genitourinary medicine (GUM) clinics are sexually active. In addition to exposing themselves to sexually transmitted infections (STIs) there is the risk of unplanned pregnancies. The National Strategy for Sexual Health and HIV ${ }^{1}$ advocates a more holistic approach to sexual health: it therefore seems reasonable that there should be an integration of contraceptive and GUM services. A national survey in $1997^{2}$ established that $79 \%$ of GUM clinics in the UK provided emergency contraception but only $14 \%$ offered a full contraceptive service. At our GUM clinic in central Birmingham, UK the only contraceptive services offered are hormonal emergency contraception and condoms. An unpublished audit of emergency hormonal contraception use in our clinic revealed that all cases of contraceptive failure were in condom users. A study in an Oxford GUM clinic ${ }^{3}$ suggested that within a specialist GUM service holistic care was being achieved and the contraceptive needs of attendees were managed appropriately. We wanted to ascertain what proportion of women attending our clinic were using reliable contraception and whether we were missing opportunities to provide better contraception.

\section{Methods}

A retrospective notes review was conducted for all new female patients attending our GUM clinic in January 2006. Only sexually active women of reproductive age were included; any pregnant or menopausal women were excluded. Demographic details of age and ethnicity were

Department of Genitourinary Medicine, Whittall Street Clinic, Birmingham, UK

Sharon Moses, MRCOG, DFFP, Senior House Officer in Genitourinary Medicine

Mia Huengsberg, MD, FRCOG, Consultant in Genitourinary Medicine

Correspondence to: Dr Sharon Moses, Contraceptive Services, UHL Trust, St Peter's Health Centre, Sparkenhoe Street, Leicester LE2 0TA, UK. E-mail: smoses@doctors.org.uk

\section{Key message points}

- A genitourinary medicine clinic may be a suitable setting for contraceptive advice and ideally provision.

- Adequacy of contraceptive use may vary with age and ethnicity.

- Sexual health services should address the needs of the population they serve in order to provide effective and holistic care.

collated, as were contraceptive method and condom use. The standard history sheet used by our clinic includes contraceptive method used and also consistency of condom use. Reliable contraception was defined as consistent condom use, hormonal methods, intrauterine contraceptive device, tubal ligation or vasectomy. Unreliable contraception included inconsistent or no condom use. Documentation of contraceptive advice and provision of a family planning leaflet were also noted.

Data were entered into an Excel $^{\mathrm{TM}}$ spreadsheet to derive frequency distributions. On account of the small number of participants, formal statistical analysis was not undertaken.

\section{Results}

In January 2006, 277 new patients attended the clinic, three were excluded due to pregnancy, six were postmenopausal and two were aged under 10 years. The age range of attendees was 15-45 (median, 21) years.

Tables 1 and 2 show the different methods of contraception utilised by women attending the clinic according to age group and ethnicity, respectively. The combined oral contraceptive pill and condoms were the most popular methods with other methods being used infrequently.

Tables 3 and 4 show adequacy of contraceptive use by age group and ethnicity, respectively. Overall, 266 (56\%) women were using adequate contraception with 59 (22\%) using inadequate contraception and 59 (22\%) using no contraception. There was documentary evidence that four women using no contraception were trying to conceive. 
Table 1 Method of contraception by age group

\begin{tabular}{|c|c|c|c|c|c|c|c|}
\hline \multirow[t]{2}{*}{ Contraceptive method } & \multicolumn{7}{|c|}{ Age (years) [n (\%)] } \\
\hline & $\begin{array}{l}\text { Total } \\
(n=266)\end{array}$ & $\begin{array}{l}<20 \\
(n=72)\end{array}$ & $\begin{array}{l}20-24 \\
(n=119)\end{array}$ & $\begin{array}{l}25-29 \\
(n=35)\end{array}$ & $\begin{array}{l}30-34 \\
(n=16)\end{array}$ & $\begin{array}{l}35-39 \\
(n=14)\end{array}$ & $\begin{array}{l}40+ \\
(n=10)\end{array}$ \\
\hline Condoms & $81(30)$ & $25(35)$ & $32(27)$ & $14(40)$ & 3 (19) & $4(29)$ & $3(30)$ \\
\hline COC & $94(35)$ & 24 (33) & $60(50)$ & $8(23)$ & $1 \quad(6)$ & 1 (7) & 0 \\
\hline Patch & 2 & 0 & 2 & 0 & 0 & 0 & 0 \\
\hline POP & 7 & 2 & 3 & 2 & 0 & 0 & 0 \\
\hline Injection & 4 & 2 & 1 & 1 & 0 & 0 & 0 \\
\hline Implant & 4 & 2 & 2 & 0 & 0 & 0 & 0 \\
\hline IUS & 1 & 0 & 0 & 0 & 1 & 0 & 0 \\
\hline IUD & 9 & 0 & 3 & 1 & 3 & 2 & 0 \\
\hline Sterilisation & 4 & 0 & 0 & 0 & 1 & 1 & 2 \\
\hline Rhythm & 1 & 0 & 1 & 0 & 0 & 0 & 0 \\
\hline None & 59 (22) & $17(24)$ & $15(13)$ & $9(26)$ & $7(44)$ & $6(43)$ & $5(50)$ \\
\hline
\end{tabular}

COC, combined oral contraceptive pill; IUD, intrauterine device; IUS intrauterine system; POP, progestogen-only pill.

Table 2 Method of contraception by ethnicity

\begin{tabular}{|c|c|c|c|c|}
\hline \multirow{2}{*}{$\begin{array}{l}\text { Contraceptive } \\
\text { method }\end{array}$} & \multicolumn{4}{|c|}{ Ethnicity [ $\boldsymbol{n}(\%)]$} \\
\hline & $\begin{array}{l}\text { Total } \\
(n=266)\end{array}$ & $\begin{array}{l}\text { Asian } \\
(n=37)\end{array}$ & $\begin{array}{l}\text { Afro- } \\
\text { Caribbean } \\
(n=70)\end{array}$ & $\begin{array}{l}\text { Caucasian } \\
(n=159)\end{array}$ \\
\hline Condoms & $81(30)$ & $12(32)$ & $29(41)$ & $40(25)$ \\
\hline COC & $94(35)$ & $11(28)$ & 19 (27) & $64(40)$ \\
\hline Patch & 2 & 0 & 1 & 1 \\
\hline POP & 7 & 0 & 1 & 6 \\
\hline Injection & 4 & 0 & 1 & 3 \\
\hline Implant & 4 & 0 & 2 & 2 \\
\hline IUS & 1 & 0 & 0 & 1 \\
\hline IUD & 9 & 2 & 3 & 4 \\
\hline Sterilisation & 4 & 0 & 1 & 3 \\
\hline Rhythm & 1 & 0 & 1 & 0 \\
\hline None & 59 (22) & 12 (32) & $12(17)$ & 35 (22) \\
\hline
\end{tabular}

$\mathrm{COC}$, combined oral contraceptive pill; IUD, intrauterine device; IUS intrauterine system; POP, progestogen-only pill.

The under-20s age group was the most likely to be using inadequate contraception, with 24 (33\%) women using condoms inconsistently. There was an increase in not using contraception in women aged 30 years and over. The over-40s were most likely to be using no contraception, with five (50\%) women not using any contraceptive method nor trying to conceive. The 20-24 years age group were most likely to use an adequate method of contraception.

Ethnicity showed a trend of Afro-Caribbean women being more likely to use condoms and using them less consistently than the other ethnic groups (23 attendees, $33 \%)$. However, Asian women were most likely to be using no contraception with $12(33 \%)$ using none and only one documented as planning a pregnancy. Caucasian women were more likely to have adequate contraception (97 attendees, 61\%).

Of the 118 women using inadequate contraception, only six $(5 \%)$ cases had documentation in the case notes of contraceptive advice or provision of a family planning leaflet.

\section{Discussion}

In our clinic population almost half the attendees (114, $43 \%$ ) have no or inadequate contraception. Where contraception is not reliable, documented advice and information regarding contraceptive services is poor. These results differ from an Oxford GUM clinic where only $18 \%$ of attendees were using inadequate contraception. ${ }^{3}$ This finding may be explained by differing ethnicity and socioeconomic status of the populations attending each clinic, although data were not given.

Although our study numbers were too small for formal statistical analysis, the overall trends provide useful information that supports national findings. ${ }^{1,4}$ The under20 age group and Afro-Caribbean women were most likely to be using inadequate contraception, with Asian women and the over-30s frequently using no contraception. The National Strategy for Sexual Health and HIV ${ }^{1}$ identifies young people, black and minority ethnic groups as needing targeted sexual health information and purports that these groups may experience barriers to accessing services (findings that are mirrored in our study results).

The young, with their high fertility and chaotic lifestyles, are less likely to be in stable relationships and may see condom use as prevention against STIs rather than pregnancy avoidance. The Omnibus survey from the National Statistics Office for $2004 / 2005^{4}$ states that in women aged 16-49 years condom use was $22 \%$. In our study the higher proportion of condom use $(30 \%)$ could reflect the younger age group and a biased population presenting to a GUM clinic. In young women the finding that condoms are used as the main method of contraception is a worrying one since the first-year user failure rate for condoms is $2-15$ per 100 women compared to $0.2-3$ per 100 women for the combined oral contraceptive pill. ${ }^{5}$

Women aged over 30 years were most likely to be using no contraception, a finding similar to that of the Omnibus survey for 2004/2005 in which reasons for not using contraception included wanting to get pregnant, not currently in a relationship and not liking contraception. It may be that women attending the GUM service are less

Table 3 Adequacy of contraceptive use by age group

\begin{tabular}{|c|c|c|c|c|c|c|c|}
\hline \multirow[t]{2}{*}{ Contraception } & \multicolumn{7}{|c|}{ Age (years) [n (\%)] } \\
\hline & $\begin{array}{l}\text { Total } \\
(n=266)\end{array}$ & $\begin{array}{l}<20 \\
(n=72)\end{array}$ & $\begin{array}{l}20-24 \\
(n=119)\end{array}$ & $\begin{array}{l}25-29 \\
(n=35)\end{array}$ & $\begin{array}{l}30-34 \\
(n=16)\end{array}$ & $\begin{array}{l}35-39 \\
(n=14)\end{array}$ & $\begin{array}{l}40+ \\
(n=10)\end{array}$ \\
\hline Adequate & $148(56)$ & $31(43)$ & $82(69)$ & $17(48)$ & $8(50)$ & $5(36)$ & $5(50)$ \\
\hline Inadequate & $59(22)$ & $24(33)$ & $22(18)$ & $9(26)$ & $1(6)$ & $3(21)$ & \\
\hline None & $59(22)$ & $17(24)$ & $15(13)$ & $9(26)$ & $7(44)$ & $6(43)$ & $5(50)$ \\
\hline Trying to conceive & $4(2)$ & 1 (1) & 0 & 1 (3) & $1(6)$ & 0 & 0 \\
\hline
\end{tabular}


Table 4 Adequacy of contraceptive use by ethnicity

\begin{tabular}{|c|c|c|c|c|}
\hline \multirow[t]{2}{*}{ Contraception } & \multicolumn{4}{|c|}{ Ethnicity [ $n(\%)]$} \\
\hline & $\begin{array}{l}\text { Total } \\
(n=266)\end{array}$ & $\begin{array}{l}\text { Asian } \\
(n=37)\end{array}$ & $\begin{array}{l}\text { Afro- } \\
\text { Caribbean } \\
(n=70)\end{array}$ & $\begin{array}{l}\text { Caucasian } \\
(n=159)\end{array}$ \\
\hline $\begin{array}{l}\text { Adequate } \\
\text { Inadequate }\end{array}$ & $\begin{array}{r}148(56) \\
59(22)\end{array}$ & $\begin{array}{r}16(43) \\
9(24)\end{array}$ & $\begin{array}{l}35(50) \\
23(33)\end{array}$ & $\begin{array}{l}97(61) \\
27(17)\end{array}$ \\
\hline None & 59 (22) & $12(33)$ & $12(17)$ & 35 (22) \\
\hline $\begin{array}{l}\text { Trying to } \\
\text { conceive }\end{array}$ & $4(2)$ & 1 (3) & 0 & $3(2)$ \\
\hline
\end{tabular}

likely to be in a long-term relationship and therefore the benefits of using reliable contraception are outweighed by side effects or perceived risks when sexual activity is unpredictable. This reinforces the need for raising awareness about all contraceptive methods and making these methods accessible to everyone.

All trainees in GUM must obtain the Diploma of the Faculty of Family Planning (DFFP) and thus have a good knowledge base for providing contraception. Women attending our GUM clinic have already made a step towards accessing sexual health services and in our clinic we seem to be missing a valuable opportunity to address these women's contraceptive needs. An audit report from a Nottingham GUM clinic in $2004^{6}$ found that over half of their patients would use a contraceptive service available within a GUM setting. We plan to conduct a prospective survey in our clinic to assess the contraceptive needs of women attending a GUM clinic so that we can reflect on our current missed opportunities and in the future address the feasibility of providing an on-site family planning service.

\author{
Statements on funding and competing interests \\ Funding None identified.
}

Competing interests None identified.

\section{References}

1 Department of Health. The National Strategy for Sexual Health and HIV. 2001. http://www.dh.gov.uk/assetRoot/04/05/89/ 45/04058945.pdf [Accessed 15 November 2006].

2 The British Co-operative Clinical Group. Provision of sexual health care of adolescents in Genitourinary Medicine Clinics in the United Kingdom. Genitourin Med 1997; 73: 453-456.

3 Mahar F, Sherrard J. Is genitourinary medicine meeting the contraception needs of clinic attendees? Int J STI AIDS 2005; 16: $543-545$.

4 O'Sullivan I, Keyse L, Park N, Diaper A, Short S. Contraception \& Sexual Health, 2004/05. 2005. http://www.statistics. gov.uk/downloads/theme_health/Contraception2004.pdf [Accessed 15 November 2006].

5 Guillebaud J. Contraception Today (5th edn). London, UK: Taylor \& Francis, 2004.

6 Kingston M, White C, Carlin E, Ahmed-Jushuf I. Genitourinary medicine; an opportunity to reduce unwanted pregnancy. Int $J$ STD AIDS 2004; 15: 192-194.

\section{CAREER PATHWAYS}

\section{Specialist Registrar in Genitourinary Medicine}

How has your career developed? I qualified as a doctor in 1994 and initially embarked upon a career in obstetrics and gynaecology. As part of my training I did a Senior House Officer (SHO) job in genitourinary medicine (GUM) and was converted more or less straight away. As I had done MRCOG I needed to do some more general medicine including 6 months of unselected medical take so I did further $\mathrm{SHO}$ jobs in HIV/general medicine and dermatology. The alternative pathway into GUM is by doing MRCP.

What does your current role entail? My job is mainly outpatient-based and I do regular HIV and general GUM clinics. I take part in the on-call rota for HIV-positive inpatients although this is non-resident so not too onerous on the whole and an attachment on the HIV inpatient ward is an essential part of our training. We also rotate through specialist GUM clinics such as Hepatitis Clinic, Herpes Clinic and Male and Female Problem Clinics. There is plenty of opportunity to get involved in teaching undergraduates as well as SHOs and nursing staff.

What is an average day like for you? Each day is different but a typical one might involve doing an outreach sex

\section{FACT FILE}

Name: Sophie Forsyth

Job title: Specialist Registrar in

Genitourinary Medicine (Flexible Trainee)

Location: Mortimer Market Centre, London, UK

Qualifications: $\mathrm{MBChB}, \mathrm{MRCOG}$, DFFP,

DipGUM

workers' clinic in the morning where I might treat syndromically for STIs and try to sort out the attendees' contraceptive needs as well. At lunchtime I might attend a meeting on the development of a new integrated sexual health and contraception service as part of my management experience. In the late afternoon I might attend an academic or research meeting to try and keep up to date with the latest findings and get involved in research myself.

\section{What are the best and worst elements of your job?}

I see myself as very lucky to be doing a job I enjoy and to be working with some inspiring colleagues both medical and non-medical. On the GUM side most patients are young and healthy and you can often quickly and easily sort out something that they may have been extremely worried and embarrassed about. HIV medicine is a rapidly expanding specialty and it is exciting to be part of something that is so important globally.

The only down sides will be familiar to most doctors I expect and involve having to do administrative duties such as rotas and organising meetings.

How do you see your job progressing in the future?

I have a year left as an SpR and then I would like to find a consultant post where I will be able to develop my interests in the sexual health of young people, HIV-positive pregnant women, and dermatology.

\section{If you were not a doctor what would you like to do?}

That's a difficult one as it took me long enough to work out that I wanted to be a GUM doctor. I'd like to think it would be something altruistic like teaching as I greatly enjoy working with young people, but some days I think I should be earning a fortune in the city!

\section{FURTHER INFORMATION}

British Association for Sexual Health and HIV (BASHH): www.bashh.org

British HIV Association (BHIVA): www.bhiva.org 